\title{
Impulsivity and overeating in children in the absence and presence of hunger
}

Citation for published version (APA):

Nederkoorn, C., Dassen, F. C. M., Franken, L., Resch, C., \& Houben, K. (2015). Impulsivity and overeating in children in the absence and presence of hunger. Appetite, 93, 57-61. https://doi.org/10.1016/j.appet.2015.03.032

Document status and date:

Published: 01/10/2015

DOI:

10.1016/j.appet.2015.03.032

Document Version:

Publisher's PDF, also known as Version of record

Document license:

Taverne

Please check the document version of this publication:

- A submitted manuscript is the version of the article upon submission and before peer-review. There can be important differences between the submitted version and the official published version of record.

People interested in the research are advised to contact the author for the final version of the publication, or visit the DOI to the publisher's website.

- The final author version and the galley proof are versions of the publication after peer review.

- The final published version features the final layout of the paper including the volume, issue and page numbers.

Link to publication

\footnotetext{
General rights rights.

- You may freely distribute the URL identifying the publication in the public portal. please follow below link for the End User Agreement:

www.umlib.nl/taverne-license

Take down policy

If you believe that this document breaches copyright please contact us at:

repository@maastrichtuniversity.nl

providing details and we will investigate your claim.
}

Copyright and moral rights for the publications made accessible in the public portal are retained by the authors and/or other copyright owners and it is a condition of accessing publications that users recognise and abide by the legal requirements associated with these

- Users may download and print one copy of any publication from the public portal for the purpose of private study or research.

- You may not further distribute the material or use it for any profit-making activity or commercial gain

If the publication is distributed under the terms of Article $25 \mathrm{fa}$ of the Dutch Copyright Act, indicated by the "Taverne" license above, 
Research report

\title{
Impulsivity and overeating in children in the absence and presence of hunger
}

\author{
Chantal Nederkoorn *, Fania C.M. Dassen, Loes Franken, Christine Resch, Katrijn Houben \\ Chantal Nederkoorn Department of Clinical Psychological Science Maastricht University, P.O. Box 616, Maastricht 6200 MD, the Netherlands
}

\section{A R T I C L E I N F O}

\section{Article history:}

Received 13 January 2015

Received in revised form 28 February 2015

Accepted 23 March 2015

Available online 1 April 2015

\section{Keywords:}

Response inhibition

Impulsivity

Food intake

Overeating

Hunger

Satiety

\begin{abstract}
A B S T R A C T
Overweight children appear to be more responsive to environmental, hedonic cues and easily overeat in the current obesogenic environment. They are also found to overeat in the absence of hunger, and this overeating seems related to impulsivity: impulsive participants are more prone to external eating. However, some studies showed that impulsive adults are also more prone to hunger cues: impulsive participants overate especially when feeling hungry. This would mean impulsive people are more reactive to both external and internal cues. The overeating was limited to palatable high energy-dense foods: hunger made them fancy a snack. In the current study, we wanted to test the interaction between impulsivity, hunger and consumption of food type in children. Impulsivity was measured in 88 children between the ages of 7 and 9 . Next, half of the participants performed a taste test before their own regular lunch and half of the participants immediately after their lunch. During the taste test, low, medium and high energydense food items were presented. Results showed that impulsive children ate more high energy-dense foods than low impulsive children, both before and after their lunch. No differences were found on low or medium energy-dense foods. Impulsive children therefore showed normal sensitivity for internal hunger and satiety cues, but abnormal response to high energy-dense foods. This might render them vulnerable to tasty temptation in the environment and to weight gain in their future.
\end{abstract}

(C) 2015 Elsevier Ltd. All rights reserved.

\section{Introduction}

Childhood obesity is a major concern nowadays. In order to fight childhood obesity effectively, it is important to know its main causes. One problem is the abundant availability of relatively cheap, palatable, high caloric foods, which can easily lead to eating more than needed. Numerous studies showed that increased portion size (Rolls, 2003), high energy density of food and the relatively low costs of energy dense foods (Drewnowski \& Specter, 2004) and aggressive advertisement of palatable high caloric foods (Andreyeva, Kelly, \& Harris, 2011; Nestle, 2006) all contribute to increased intake and obesity. However, not all children become obese, suggesting that some children might be more responsive to the obesogenic environment than others. In 2013 , around $12.6 \%$ of the children were obese in the United States and 6.8\% in Western Europe ( $\mathrm{Ng}$ et al., 2014). Indeed, research showed that overweight children respond stronger to food cues (Carnell \& Wardle, 2008; Halford, Gillespie, Brown, Pontin, \& Dovey, 2004; Jansen et al., 2003) and are less effective in inhibiting their responses towards food cues (Nederkoorn, Coelho, Guerrieri, Houben, \& Jansen, 2012), compared to children

\footnotetext{
* Corresponding author.

E-mail address: c.nederkoorn@maastrichtuniversity.nl (C. Nederkoorn).
}

with a healthy weight. Overweight children might act more in response to hedonic hunger, instead of relying on homeostatic cues of hunger and satiety (Appelhans, 2009). This is in line with the externality theory of Schachter (1971; Schachter \& Rodin, 1974), which states that obese individuals are more reactive to external cues and less sensitive to internal cues, like hunger and satiety. To measure hedonic eating, a frequently used paradigm is eating in the absence of hunger. During this procedure, children are first asked to eat until sated during a meal and next, to perform a taste test with palatable snack foods. Results showed that overweight children overeat more in the absence of hunger (Fisher \& Birch, 2002; Kral et al., 2012), and overeating in the absence of hunger is predictive of weight gain and becoming overweight in the future (Shunk \& Birch, 2004). An extensive literature is focused on eating in the absence of hunger, using it for instance as an outcome variable for treatment for overweight children (Boutelle et al., 2011). Eating in the absence of hunger is considered an index of disinhibited eating (Francis, Ventura, Marini, \& Birch, 2007) and lower impulsivity appeared related to more responsiveness to internal satiety cues (Tan \& Holub, 2011), whereas higher impulsivity has been related to higher external eating (Farrow, 2012; Hou et al., 2011; Jasinska et al., 2012) and more responsiveness to food cues (for an overview, see: Van den Akker, Stewart, Antoniou, Palmberg, \& Jansen, 2014).

The fact that high impulsive people eat more than low impulsive people when being sated does not exclude the possibility they 
might also eat more when feeling hungry. Hunger is a general trigger to eat; it increases reactivity to food cues (Brunstrom, Yates, \& Witcomb, 2004) and makes especially high caloric foods more rewarding (Siep et al., 2009). Perhaps it is an even more important trigger for impulsive people. Indeed, Nederkoorn, Guerrieri, Havermans, Roefs, and Jansen (2009) found that high impulsive, disinhibited participants tend to eat more than low impulsive participants, but especially when feeling hungry. Without hunger, no differences in intake were found between low and high impulsive participants. This finding was replicated in another study, in which variety of food was manipulated (Guerrieri, Stanczyk, Nederkoorn, \& Jansen, 2012). Impulsive, reward sensitive participants ate more during a varied food taste test than during a monotonous food test, but only when feeling hungry. Without hunger, variety of food did not influence intake. In low impulsive participants, hunger and variety did not affect intake at all. These findings suggest impulsive people are more sensitive not only to external but also to internal cues: hunger is the best sauce and by increasing the savour of food, hunger might increase the demand on inhibitory control to prevent overeating. In both experiments, the hunger was modest: participants only withheld from eating for several hours. Mild hunger might therefore be enough to trigger disinhibited eating. However, in both studies, adults were measured. This raises the question whether children react similarly, meaning that more impulsive children tend to overeat primarily when feeling hungry and not while sated. Alternatively, it is possible that impulsive children are not able to control their intake of palatable foods, irrespective of their level of satiation, and overeat in both conditions. In general, inhibitory control in children is less developed compared to adults, due to immature prefrontal activation (Bunge, Dudukovic, Thomason, Vaidya, \& Gabrieli, 2002), which might cause them to indulge in tasty foods under all circumstances. Adults might have learned to control their intake in less tempting situations and only fail to inhibit themselves when the desire to eat is high.

In the present study, we therefore wanted to test whether impulsive children eat more compared to low impulsive children, when hungry or sated. Impulsivity is measured during a first test day and hunger is manipulated during a second test day, in order to isolate these effects. During the taste test, low, medium and high energy-dense foods are presented. Based on the previous finding that impulsive participants especially overeat high energydense (HED) foods (Nederkoorn et al., 2009), we expect that high impulsive children eat particularly more HED foods, compared to low impulsive children. It is not expected that impulsivity has an influence on intake of low or medium energy dense (LED or MED) foods. Moreover, we expect that the group differences will be more pronounced in the hunger condition, meaning that we expect a three-way interaction between hunger, impulsivity and energy-density.

\section{Methods}

Participants

A total of 92 children between 7 and 9 years old were tested on two separate days. Four children were excluded from analyses; one because of technical problems with the task, two children did not understand the task properly and one child appeared to be an influential case on the dependent variable (Cook's distance $>4 / n$ ). The mean age of the remaining 88 children was 8.1 ( $\mathrm{SD}=.75)$, mean $\mathrm{BMI}$ was $16.2(\mathrm{SD}=2.3$ ) and mean BMI Z-score was -.068 (SD = .93). The sample consisted of 32 boys and 57 girls (see also the demographic characteristics in Table 1 ).

\section{Measures}

Response inhibition was measured with an adapted version of the Stop signal task (Logan, Schachar, \& Tannock, 1997). This task involves a go and stop task. The go task was a choice reaction time task in which participants had to decide as fast as possible whether a square was presented on the left or right side of the computer screen, by pressing a corresponding button. In $25 \%$ of the trials (the stop trials) an auditory stop signal $(1000 \mathrm{~Hz}, 100 \mathrm{~ms})$ was presented, indicating that subjects had to inhibit their response. Initially, the stop signal delay was set at $250 \mathrm{~ms}$ after the presentation of the go signal and then adjusted dynamically depending on the responses of the subject. After a correct inhibition of the response, the delay was increased by $50 \mathrm{~ms}$, making the next trial more difficult. After an incorrect response, the delay is decreased by $50 \mathrm{~ms}$, making the next trial somewhat easier. The two variables measured in this task are the reaction time (RT) and the stop delay. Stop signal reaction time (SSRT) is calculated by subtracting the mean stop delay from the mean reaction to the go-trials. Higher SSRTs mean that children needed more time to inhibit a response and are indicative of less effective response inhibition.

Hunger was measured on a scale ranging from 1 (not hungry at all) to 10 (very hungry). The meaning of the numbers was visually clarified with a manikin with an empty stomach above the number 1 , a manikin with a half full stomach above the numbers 5 and 6 and a manikin with a full stomach above the number 10 . In addition, the experimenter explained the meaning of the numbers to each child.

An ad lib taste test was used to measure food intake. Each child received 6 bowls, of which 2 bowls were filled with LED foods (150 g grapes, $78 \mathrm{kcal}$ per $100 \mathrm{~g}, 120 \mathrm{~g}$ carrots, $33 \mathrm{kcal}$ per $100 \mathrm{~g}$ ), two were filled with MED foods ( $37 \mathrm{~g}$ crackers, $377 \mathrm{~g}$ per $100 \mathrm{~g}$ and $70 \mathrm{~g}$ gingerbread, $309 \mathrm{kcal}$ per $100 \mathrm{~g}$ ) and two filled with HED foods (180 g M\&Ms, $519 \mathrm{kcal}$ per $100 \mathrm{~g}$ and $65 \mathrm{~g}$ crisps, $542 \mathrm{kcal}$ per $100 \mathrm{~g}$ ). The child was asked to rate the taste of each food on a 3 point scale

Table 1

Demographic characteristics and test scores of the participants.

\begin{tabular}{|c|c|c|c|c|}
\hline & $\begin{array}{l}\text { Before lunch } \\
\text { Low impulsive }\end{array}$ & $\begin{array}{l}\text { Before lunch } \\
\text { High impulsive }\end{array}$ & $\begin{array}{l}\text { After lunch } \\
\text { Low impulsive }\end{array}$ & $\begin{array}{l}\text { After lunch } \\
\text { High impulsive }\end{array}$ \\
\hline $\mathrm{N}$ & 23 & 22 & 21 & 22 \\
\hline Age & $8.3(.7)$ & $8.0(.8)$ & $8.0(.8)$ & $8.1(.7)$ \\
\hline Proportion of boys & 26.1 & 40.9 & 23.8 & 50 \\
\hline BMI & $15.7(1.3)$ & $16.0(2.3)$ & $16.2(1.7)$ & $16.8(3.3)$ \\
\hline BMI Z-score & $-.25(.8)$ & $-.12(.86)$ & $.03(.86)$ & $.08(1.2)$ \\
\hline Hunger & $8.0(1.8)$ & $7.1(1.9)$ & $5.5(1.9)$ & $5.8(1.9)$ \\
\hline SSRT (in ms) & $279.0(51.8)$ & $408.4(63.9)$ & $286.7(36.4)$ & $410.2(59.1)$ \\
\hline Total intake (in kcal) & $336.4(121.8)$ & $385.2(130.4)$ & $262.6(113.9)$ & $312.7(115.5)$ \\
\hline HED intake & $230.7(100.6)$ & $279.1(151.7)$ & $168.2(116.2)$ & $226.1(123.2)$ \\
\hline MED intake & $59.4(39.2)$ & $67.6(48.1)$ & $61.6(45.3)$ & $52.5(36.9)$ \\
\hline LED intake & $46.3(42.8)$ & $38.5(38.0)$ & $32.8(33.8)$ & $34.0(39.9)$ \\
\hline
\end{tabular}




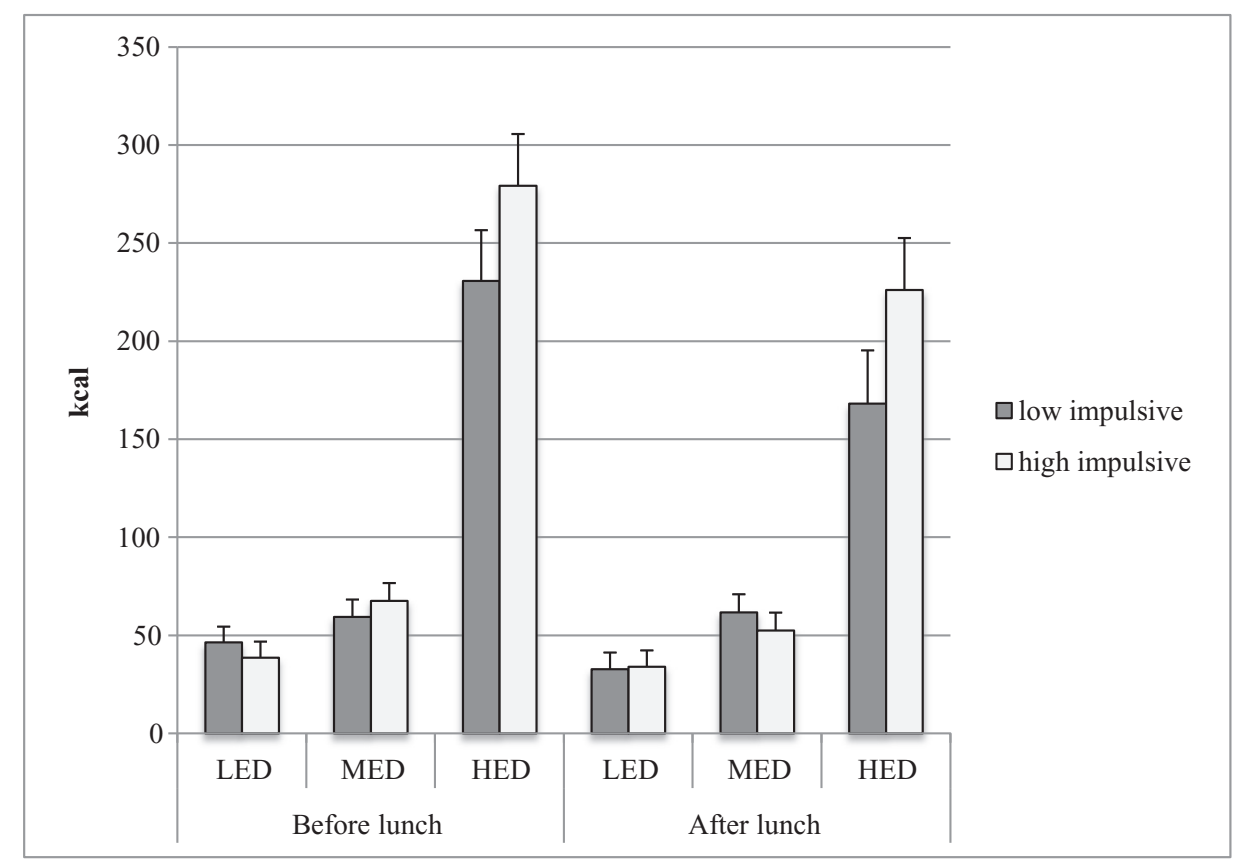

Fig. 1. Mean consumption (with S.E.M.) of LED, MED and HED foods of low and high impulsive children, before and after lunch.

( 3 = happy, 2 = neutral or 1 = frowning face) and was informed (s)he could eat as much as (s)he wanted. The taste test lasted 10 minutes. Each bowl was weighed before and after the taste test and caloric intake was measured, separately for LED, MED and HED foods.

\section{Procedure}

On the first test day, response inhibition, weight and height were measured. Each child was measured individually. Most children (84\%) were measured in the morning. ${ }^{1}$ The child received a small reward (pencil or eraser) and returned to the classroom. On the second testing day, 1-4 weeks later, each child was randomised in the before or after lunch condition. In both conditions, children were tested during the lunch break, just before or directly after they ate their lunch. The children ate their own regular lunch, which in The Netherlands typically consists of several sandwiches and a drink. The children filled out their hunger scores and next performed the taste test. The children were tested in small groups, seated alone at a separate table not facing each other.

\section{Statistical analyses}

Based on the median score on the stop signal task (SSRT $=345)$, children were divided in a low impulsivity $(n=44, M=282.6$, $\mathrm{SD}=44.8)$ and a high impulsivity $(\mathrm{n}=44, \mathrm{M}=409.3, \mathrm{SD}=60.8)$ group.

With independent samples t-tests, it was tested whether children in the two conditions (before or after lunch) or groups (low and high impulsivity) differed in age, BMI, percentage overweight, hunger and liking of foods. With a chi-square test, it was tested whether the groups differed in their boy-girl ratio.

A 3 (type of food: LED, MED and HED) $\times 2$ (condition) $\times 2$ (impulsivity: high or low) mixed measures ANOVA was used to test whether impulsivity interacted with hunger and type of consumed food. Gender was initially included as a covariate because a group difference in boy-girl ratio was found (see below). This

\footnotetext{
1 Time of testing was not related to performance on the stop signal task $(r=-.021$, $p=.85)$.
}

covariate was however not significant and did not change the pattern of results. To preserve power, gender was therefore excluded as a covariate.

To test whether children differed in their liking of the food, a 3 (type of food: LED, MED and HED) $\times 2$ (condition) $\times 2$ (impulsivity: high or low) mixed measures ANOVA was used, with liking of the food as dependent variable.

Finally, it is tested whether impulsivity is related to weight, with a Pearson correlation.

\section{Results}

The children in the two conditions (before and after lunch) did not differ in age, BMI, percentage overweight or liking of the foods (all $t<.6$ ) or in gender (Chi-square $=.15$ ). The children in the conditions differed significantly in self-reported hunger $(t(86)=4.8$, $p<.001, \eta^{2}$ partial $=.22$ ), indicating the manipulation was successful (means are revealed in Table 1 ).

The two groups (low and high impulsive children) did not differ in age, BMI, percentage overweight, hunger or liking of the foods (all $t$ 's $<1.02$ ). There were relatively more boys in the high impulsive group, compared to the low impulsive group (Chi-square $=.4 .03$, $p=.045)$.

The 3 (type of food: LED, MED and HED) $\times 2$ (condition) $\times 2$ (impulsivity: high or low) mixed measures ANOVA showed a main effect of food type $\left(F(2,168)=134.3, p<.001, \eta^{2}\right.$ partial $\left.=.62\right)$; the children ate most calories from HED foods and least from LED foods (see Fig. 1). There was also a main effect of condition $(F(1,84)=8.5, p=.005$, $\left.\eta_{\text {partial }}=.092\right)$; children ate more before than after their lunch. In addition, there was a significant effect of impulsivity $(F(1,84)=4.5$, $p=.037, \eta^{2}$ partial $\left.=.051\right)$, indicating that high impulsive children ate more than low impulsive children. Moreover, there was a significant interaction effect between impulsivity and food type $\left(F(2,166)=4.6, p=.011, \eta^{2}\right.$ partial $\left.=.052\right)$. Post hoc tests showed that high impulsive children only ate more of $\operatorname{HED}$ foods $(F(1,83)=4.03$, $p=.048, \eta^{2}$ partial $\left.=.046\right)$ and not of the MED or LED foods $(F \mathrm{~s}<.2)$. There was also a marginal significant interaction effect between condition and food type $\left(F(2,168)=2.93, p=.056, \eta^{2}\right.$ partial $\left.=.034\right)$ : 
before lunch, the children ate significantly more HED foods than after lunch $\left(F(1,84)=4.78, p=.032, \eta^{2}\right.$ partial $\left.=.054\right)$. For the other food types, no effect of condition was found $(F \mathrm{~s}<1.05)$. The interaction between impulsivity and condition was not significant $(F(1,84)=0.48, p=.83$, $\eta^{2}$ partial $=.001$ ) and the 3-way interaction between type of food, condition and impulsivity was also not significant $(F(2,168)=.47$, $p=.625, \eta_{\text {partial }}^{2}=.006$ ).

When testing the liking of the food, the 3 (type of food: LED, MED and HED) $\times 2$ (condition) $\times 2$ (impulsivity: high or low) mixed measures ANOVA showed a main effect of food type $(F(2,168)=29.7$, $\left.p<.001, \eta_{\text {partial }}^{2}=.26\right)$ : the children liked the HED foods better than both the MED foods $\left(F(1,84)=35.3, p<.001, \eta^{2}\right.$ partial $\left.=.30\right)$ and the LED foods $\left(\mathrm{F}(1,84)=64.0, \mathrm{p}<.001, \eta^{2}\right.$ partial $=.43 ; M$ liking of HED foods $=2.9, \mathrm{SD}=.24$, MED foods $=2.51, \mathrm{SD}=.5$ and $\mathrm{LED}$ foods $=2.4$, $\mathrm{SD}=.54)$. No significant effects of the hunger manipulation, impulsivity or their interaction on liking of foods were found (all $F \mathrm{~s}<1.5$ ).

Finally, it is tested whether impulsivity was related to BMI Z-scores. The correlation appeared not significant $(r=1, p=.35)$.

\section{Discussion}

The present study showed that all children liked the HED foods more and ate more of it, compared to the LED and MED foods. However, impulsive children ate more HED foods than low impulsive children during an ad lib taste test. No differences were found on MED or LED foods. This conforms to previous findings (Nederkoorn et al., 2009) and indicates that impulsive children are especially vulnerable to overeat on tasty snack foods, but not on healthier low caloric foods. The impulsive children did not like these foods more than low impulsive children according to their selfreported ratings, their problem therefore appears purely that they are less able to stop on-going eating behaviour.

Hunger also had a significant effect: the children ate more before lunch than after lunch. However, hunger and impulsivity did not interact: both directly before and after lunch, impulsive children ate more HED foods. This is not in concordance with previous studies of Nederkoorn et al. (2009) and Guerrieri et al. (2012), who found that impulsive participants especially ate more when feeling hungry. Speculating on what caused this difference, it is possible that children are less adequate in inhibiting their responses then adults (Bunge et al., 2002). The impulsive children might therefore be unable to control their intake in both occasions. Adults might have learned to control their intake in less tempting situations and only fail to do so when the enticement is great. This would suggest that impulsive children learn some control over snack eating during maturation, although not in all occasions.

Alternatively, the hunger manipulations differed between the studies, which could explain their differential moderation of the effect of impulsivity on food intake. In the current study, the manipulation of hunger and satiety was not very strong: the children reported to feel still moderately hungry after their lunch and the main effect of the lunch on food intake was small. It is possible that with a stronger satiety induction, the impulsive children would refrain from eating too much. That being said, the lunch of the children who participated in the present study represents the normal situation for children in The Netherlands, thereby giving high external validity to the results with regard to overeating after a regular meal.

In sum, impulsive children appeared vulnerable to overeat tasty snack foods, but showed normal sensitivity for internal hunger and satiety cues. Although high impulsive children ate more than low impulsive children, the effect size in the current study was quite small. Impulsive children ate on average $48 \mathrm{kcal}$ more than the low impulsive children. This is around $4 \%$ of the recommended daily calories per day (1200 kcal for girls and 1400 for boys; American Heart Association, 2015). This might seem trivial, but a daily small surplus of energy might over time lead to more weight gain and even overweight (Hill, Wyatt, Reed, \& Peters, 2003). In the present study, impulsivity was not significantly related to weight at the time of testing. However, several studies showed that impulsivity is related to weight gain and overweight (Braet, Claus, Verbeken, \& Van Vlierberghe, 2007; Francis \& Susman, 2009; Nederkoorn, Braet, Van Eijs, Tanghe, \& Jansen, 2006; Nederkoorn, Houben, Hofmann, Roefs, \& Jansen, 2010; Thamotharan, Lange, Zale, Huffhines, \& Fields, 2013; but see also Scholten, Schrijvers, Nederkoorn, Kremers, \& Rodenburg, 2014). The tendency to overeat in the young impulsive children might therefore over time result in overweight.

To conclude, the present study shows that impulsive children are more prone to overeating HED foods then low impulsive children, irrespective of their hunger level. This might render them vulnerable to tasty temptation in the environment and to weight gain in their future.

\section{References}

American Heart Association (2015). Dietary recommendations for healthy children. Available from http://www.heart.org/HEARTORG/GettingHealthy/Dietary -Recommendations-for-Healthy-Children_UCM_303886_Article.jsp.

Andreyeva, T., Kelly, I. R., \& Harris, J. L. (2011). Exposure to food advertising on television. Associations with children's fast food and soft drink consumption and obesity. Economics \& Human Biology, 9, 221-233.

Appelhans, B. M. (2009). Neurobehavioral inhibition of reward-driven feeding. Implications for dieting and obesity. Obesity, 17, 640-647.

Boutelle, K. N., Zucker, N. L., Peterson, C. B., Rydell, S. A., Cafri, G., \& Harnack, L. (2011) Two novel treatments to reduce overeating in overweight children. A randomized controlled trial. Journal of Consulting and Clinical Psychology, 79, 759.

Braet, C., Claus, L., Verbeken, S., \& Van Vlierberghe, L. (2007). Impulsivity in overweight children. European child \& Adolescent Psychiatry, 16, 473-483.

Brunstrom, J. M., Yates, H. M., \& Witcomb, G. L. (2004). Dietary restraint and heightened reactivity to food. Physiology \& Behavior, 81, 85-90.

Bunge, S. A., Dudukovic, N. M., Thomason, M. E., Vaidya, C. J., \& Gabrieli, J. D. (2002) Immature frontal lobe contributions to cognitive control in children. Evidence from fMRI. Neuron, 33(2), 301-311.

Carnell, S., \& Wardle, J. (2008). Appetite and adiposity in children. Evidence for a behavioral susceptibility theory of obesity. The American Journal of Clinical Nutrition, 88, 22-29.

Drewnowski, A., \& Specter, S. E. (2004). Poverty and obesity. The role of energy density and energy costs. The American Journal of Clinical Nutrition, 79, 6-16.

Farrow, C. V. (2012). Do parental feeding practices moderate the relationships between impulsivity and eating in children? Eating Behaviors, 13, 150-153.

Fisher, J. O., \& Birch, L. L. (2002). Eating in the absence of hunger and overweight in girls from 5 to $7 \mathrm{y}$ of age. The American Journal of Clinical Nutrition, 76, 226-231.

Francis, L. A., \& Susman, E. J. (2009). Self-regulation and rapid weight gain in children from age 3 to 12 years. Archives of Pediatrics \& Adolescent Medicine, 163, 297-302.

Francis, L. A., Ventura, A. K., Marini, M., \& Birch, L. L. (2007). Parent overweight predicts daughters' increase in BMI and disinhibited overeating from 5 to 13 years. Obesity, 15, 1544-1553.

Guerrieri, R., Stanczyk, N., Nederkoorn, C., \& Jansen, A. (2012). Reward-sensitive women overeat in a varied food environment, but only when hungry. Eating Behaviors, 13, 317-320.

Halford, J. C., Gillespie, J., Brown, V., Pontin, E. E., \& Dovey, T. M. (2004). Effect of television advertisements for foods on food consumption in children. Appetite 42, 221-225.

Hill, J. O., Wyatt, H. R., Reed, G. W., \& Peters, J. C. (2003). Obesity and the environment Where do we go from here? Science, 299, 853-855.

Hou, R., Mogg, K., Bradley, B. P., Moss-Morris, R., Peveler, R., \& Roefs, A. (2011). External eating, impulsivity and attentional bias to food cues. Appetite, 56, 424-427.

Jansen, A., Theunissen, N., Slechten, K., Nederkoorn, C., Boon, B., Mulkens, S., et al. (2003). Overweight children overeat after exposure to food cues. Eating Behaviors, $4(2), 197-209$.

Jasinska, A. J., Yasuda, M., Burant, C. F., Gregor, N., Khatri, S., Sweet, M., et al. (2012). Impulsivity and inhibitory control deficits are associated with unhealthy eating in young adults. Appetite, 59, 738-747.

Kral, T. V., Allison, D. B., Birch, L. L., Stallings, V. A., Moore, R. H., \& Faith, M. S. (2012). Caloric compensation and eating in the absence of hunger in 5- to $12-\mathrm{y}$-old weight-discordant siblings. The American Journal of Clinical Nutrition, 96, 574-583.

Logan, G. D., Schachar, R. J., \& Tannock, R. (1997). Impulsivity and inhibitory control. Psychological Science, 8, 60-64

Nederkoorn, C., Braet, C., Van Eijs, Y., Tanghe, A., \& Jansen, A. (2006). Why obese children cannot resist food. The role of impulsivity. Eating Behaviors, 7, 315-322.

Nederkoorn, C., Coelho, J. S., Guerrieri, R., Houben, K., \& Jansen, A. (2012). Specificity of the failure to inhibit responses in overweight children. Appetite, 59, 409-413.

Nederkoorn, C., Guerrieri, R., Havermans, R. C., Roefs, A., \& Jansen, A. (2009). The interactive effect of hunger and impulsivity on food intake and purchase in a virtual supermarket. International Journal of Obesity, 33, 905-912.

Nederkoorn, C., Houben, K., Hofmann, W., Roefs, A., \& Jansen, A. (2010). Control yourself or just eat what you like? Weight gain over a year is predicted by an interactive effect of response inhibition and implicit preference for snack foods. Health Psychology, 29, 389. 
Nestle, M. (2006). Food marketing and childhood obesity. A matter of policy. New England Journal of Medicine, 354, 2527-2529.

Ng, M., Fleming, T., Robinson, M., Thomson, B., Graetz, N., Margono, C., et al. (2014). Global, regional, and national prevalence of overweight and obesity in children and adults during 1980-2013. A systematic analysis for the Global Burden of Disease Study 2013. The Lancet, 384, 766-781.

Rolls, B. J. (2003). The supersizing of America. Portion size and the obesity epidemic. Nutrition Today, 38, 42-53.

Schachter, S. (1971). Some extraordinary facts about obese humans and rats. American Psychologist, 26, 129-144. doi:10.1037/h0030817.

Schachter, S., \& Rodin, J. (1974). Obese humans and rats. Washington, DC: Erlbaum/ Halsted.

Scholten, E. W., Schrijvers, C. T., Nederkoorn, C., Kremers, S. P., \& Rodenburg, G. (2014) Relationship between impulsivity, snack consumption and children's weight. PLoS ONE, 9(2), e88851.

Shunk, J. A., \& Birch, L. L. (2004). Girls at risk for overweight at age 5 are at risk for dietary restraint, disinhibited overeating, weight concerns, and greater weight gain from 5 to 9 years. Journal of the American Dietetic Association, 10, 11201126.

Siep, N., Roefs, A., Roebroeck, A., Havermans, R., Bonte, M. L., \& Jansen, A. (2009). Hunger is the best spice. An fMRI study of the effects of attention, hunger and calorie content on food reward processing in the amygdala and orbitofrontal cortex. Behavioural Brain Research, 198(1), 149-158.

Tan, C. C., \& Holub, S. C. (2011). Children's self-regulation in eating. Associations with inhibitory control and parents' feeding behavior. Journal of Pediatric Psychology, 36, 340-345.

Thamotharan, S., Lange, K., Zale, E. L., Huffhines, L., \& Fields, S. (2013). The role of impulsivity in pediatric obesity and weight status. A meta-analytic review. Clinical Psychology Review, 33, 253-262.

Van den Akker, K., Stewart, K., Antoniou, E. E., Palmberg, A., \& Jansen, A. (2014). Food cue reactivity, obesity, and impulsivity. Are they associated? Current Addiction Reports, 1, 301-308. 